\title{
THE INITIATION OF PHARYNGEAL VOICE AND EARLY SPEECH
} LESSONS IN THE LARYNGECTOMEE S. Bauman, M.A.

Certain established speech therapy procedures exist for the laryngectomized patient and are easily found in the literature which exists today $\left({ }^{1},{ }^{2}\right)$. There does however, appear to be a need for more explicit details concerning the initiation of voice and early speech lessons.

Surgical removal of the vocal cords does not necessarily result in permanent aphonia. The human organism with its ability to adapt can, in most cases, readjust and produce, with the tissues of the pharynx, a fricative noise which can be modified to resemble voice.

In some cases where trauma or necessary sur. gical procedures have eliminated a large amount of tissue at the back of the tongue and in the pharyngeal wall, so that an adequate closure is not possible, the production of the psuedo voice is difficult, if not impossible. For these patients an artificial aid is required. The mechanical or electrical larynx should be considered. ${ }^{3}$

With most other laryngectomeees the speech therapist attempts to teach the oesophageal voice method $(0 \mathrm{~V} \mathrm{M})$ or the pharyngeal voice method (P V M).

In the OVM air is swallowed, like food, and driven into the oesophagus. By putting pressure on the stomach muscles the air is forced back up and with throat constriction vibration is set up which resembles a belch. This sound is modified to become the new voice.

In the P V M the air is swallowed deep into the pharynx, "locked" there, and then forced out. The resultant vibration is the beginning of the new voice.

The $\mathrm{O} \mathrm{V} \mathrm{M}$ is sometimes unacceptable to patients, especially women, because of the emphasis on assuming a kinaesthetic set similar to that required for belching. In addition, the early belches are fairly loud explosive sounds which seem somewhat uncontrollable and disquieting. In the $\mathrm{P} \mathrm{V} \mathrm{M}$ it seems that the shorter passage of air, in and out, requires less time and effort and is therefore easier and quicker. The initial voice, although softer, appears to be smoother in quality, more even-flowing and continuous. Finally it is less interrupted in phraseology.

Most patients master the P V M without difficulty. ${ }^{4}$ To aid them it is sometimes advisable to begin with explanations and activities to suggest the $\mathrm{OVM}$ (up to the point of the belch) in order to stimulate the mental image and kinaesthetic impression of the action required. (See Stage V).

Whatever the technique attempted, it is not essential for the speech therapist to be able to demonstrate the new voice pattern. Some authorities (5. p 15; 6. p 5.) believe this to be essential, but the writer has found it unnecessary. The use of aerated-sherbet mixtures is also a matter of some controversy. Gaseous liquid intake is advocated by some speech therapists who maintain that it helps the patient to swallow air and then regurgitate it. For the $\mathrm{P} V \mathrm{M}$ liquids appear to be dispensable. During practice sessions, the patient swallows a great deal of air, even to the extent of becoming uncomfortably flatulent. Aerated liquids only too quickly hasten his discomfort.

\section{STAGES IN THE INITIATION OF THE PHARYNGEAL VOICE METHOD}

Stage 1: The therapist should start with relaxation $^{\tau}$ in order that the patient gets an understanding of

(a) tension, force and pressure,

(b) too flaccid a physical attitude,

(c) optimal tonicity.

This is the basis of therapy, as specific areas of tension in an overall relaxed body, are the keys to success. The generally relaxed physical attitude aids in attaining a relaxed state of mind, free from overanxiety and hampering fears.

Stage II. The patient proceeds directly from the relaxation couch to relaxed walking.

Often a person can become quite tense sitting still and trying to relax, but many tensions disappear when the patient is walking along with a comfortable, easy stride, with arms free and swinging and breathing deeply.

With a slight quickening of the pace it is easy to gulp in air (like a fish) and swallow it by forcing it right back past the pharynx.

Stage III. Ask the patient to hold his breath and feel tension in the region of the diaphragm. Rather than use technical terms such as "Tense your diaphragm", it is advisable for the therapist 
to say "Feel tension here", and to indicate manually exactly where the tension is required. The case should get the kinaesthetic stimulation by feeling how the therapist herself stiffens the 'area and makes it tense.

Now the therapist should put it to the patient that when the area of the diaphragm is tensed, some other part of the body becomes tense. By tensing the diaphragm the back of the throat is tensed and the back of the tongue is raised slightly. (Partly reciprocal action and partly sug. gestion.)

Stage IV: The patient should copy the therapist's action of:

(1) placing the tip of the tongue against the gums of the lower teeth,

(2) keeping the centre of the tongue flat on the floor of the mouth,

(3) and raising the back of the tongue to make a posterior closure (as for the ' $k$ ' sound.)

This action is called "locking" and the case must be conditioned to take up this position quickly and efficiently, on demand ${ }^{\mathrm{s}}$ :

He must take in air, swallow it inlo the back of the throat, hold his breath, feel tension in the area of the diaphragm and throat and immediately "lock."

Stage V. Explain to the case how normal speech is produced:-

(1) The air is breathed in through the mouth and nose and goes to the lungs. It then comes up from the lungs-

(2) the vocal cords come together (almost in an unconscious way),

(3) air passes through them and sets up vibrations.

(4) These vibrations become voice.

The laryngectomee has no vocal folds and the air which he breathes in, enters the hole in the throat and passes into the lungs and also comes out through the same opening in the throat.

Air taken in through the mouth and nose is swallowed down, as if to the stomach, just as food is swallowed into the stomach.

The explanation of pharyngeal voice is as follows:-

(1) Swallowed air comes up the oesophagus to the back of the throat.

(2) Certain tissues are brought together by constriction at the back of the throat to take the place of the vocal cords.

(3) The air will pass these approximating tissues and set up vibrations,

(4) these vibrations result in voice.

Nelson ( ${ }^{\mathrm{p}} \mathrm{p}$ 19) says that the air comes up to "vibrate against the fold of the oesophagus, scar tissue and bones of the throat, and the palate and other resonators."

This is valuable information for the speech therapist, but need not be available to the patient. Just as we approximate our vocal folds almost unconsciously, the laryngectomee will approximate areas at the back of the throat without being burdened with anatomical details which he cannot understand very well and which will confuse him and thereby make him nervous and anxious. The normal speaker is not aware of how he moves his vocal folds and therefore the laryngectomee should not be required to give his adaptation undue attention. A kinaesthetic understanding is more important than many detailed and scientific explanations.

It is of the utmost importance that the therapist should let the patient find his own adaptation as regards the approximation of tissues for producing voice.

Stage VI. The co-ordinating phase:

Guide the patient as follows:-

(1) Walk briskly and easily.

(2) Gulp in air through the mouth,

(3) swallow the air past the back of the mouth,

(4) hold it there by tensing the diaphragm and throat.

(5) "Lock" very effectively.

(6) Push the air out immediately after the "lock". Do not say " $k$ " which is the position being held, but let the sound come out "Ah." (The sound must be "triggered" off immediately after a very firm "lock".) ( ${ }^{B}$ p 44).

The resultant sound will be the voice which is to be developed. Keep repeating this procedure many times, allowing short rests if the patient becomes very bloated from swallowing too much air.

Occasional failure to produce this voice is to be expected as the skill is only newly acquired and has yet to be firmly established and perfected. The patient should attempt to retain and recall the kinaesthetic impression of what he did when he produced an adequate sound and try to reproduce it over and over again. Failure may be due to the exertion of too much diaphragm pressure or to an inadequately firm "lock."

This procedure is repeated for as many lessons as required in order to enable the patient to produce voice on demand.

Once he can produce the sound (voice) on demand, he can dispense with the walking activity for by this time he is able to swallow air effectively and is not dependent on the inrush of air provided by the brisk walking. When seated the ' aticnt should be in a comfortable chair with a back support. The legs should not be crossed. ( $\left.{ }^{8} \mathrm{p} 46\right)$.

By shaping the mouth the voice changes from a noise to recognizable vowel sounds. Practice is then directed towards lengthening the vowel sounds. The patient then proceeds to practice diphthongs.

The case can now be made aware of his ability to make buccal sounds. If possible, this ability 
should not be made clear to him until such time as he has learned to produce voice. Patients who realise that they can communicate with buccal speech often perfect its use quite skilfully and then persist in using it, to the detriment of learning to use the new voice.

The ability to produce sounds which are not dependent on voice suddenly widens the whole horizon of the patient.

The unvoiced consonants and the vowels or diphthongs are blended together to produce the first nonsense words. Similarly, voiced consonants and vowels or diphthongs are blended. Care should be taken to ensure that the patient blends effectively from the start.

Blending should not be isolated drill but should be practiced through the introduction of meaning. ful words almost immediately. This provides strong motivation for the patient. From monosyllabic words the patient attempts two and three syllabled words. Phrases and sentences should be introduced without delay.

It is not uncommon to find a laryngectomee experiencing some difficulty with "i", " $r$ ", "m" and " $n$ " sounds. These sounds should not be allowed to effect the patient unduly and he should not avoid these sounds. By attempting them to the best of his ability each time they confront him, he will find that they will "develop" in the speech pattern without much difficulty. The "h" sound is the only one which the laryngectomee does not master.

The clinician should prepare the case for a possible increase in coughing when the speech activity first begins. This should disappear about a week after the introduction of voice activity. He may also feel discomfort from flatulence which is caused by the uneconomical loss of air into the stomach. This flatulence disappears as he becomes more proficient. Any indications of voice from the trachea should be eliminated by decreasing general tension and the force and pressure on the diaphragm. $\left({ }^{8},{ }^{\circ}\right)$.

As soon as the patient is speaking in sentences, the clarity of the speech performance should be checked frequently by giving formal and informal intelligibility tests. The therapist alone, and then an audience, listen and watch the speaker (auditory and visual cues) and then listen without watching (auditory cues only). Audibility and intellegibility are also checked over the telephone and from a playback on a tape recorder. (Auditory cues only).

When the laryngectomee has regained the art of producing voice and speech, he should reintroduce into his speaking activities all the auxilliary actions that accompany dynamic communication such as a facil expression, pleasant hand movements and short phrases which the normal person continually uses such as "Oh, really", "Is that so," "Pardon", etc.

Throughout therapy and especially in the initial stages the patient should feel that the whole procedure is easy, and because of their anatomical structure, perfectly natural and attainable.

Often the patient presents a psychological picture not unlike that of the dysphemic. Social situations are feared and communication is avoided, because it is easier to withdraw than to watch the reactions of the auditors. They are responsive to the reactions of the listeners (who hear this somewhat unfamiliar voice) in just the same way as the stutterer reacts when he sees the listener uncomfortable in the face of his nonfluency.

The emotional reactions of the patient are not overcome as rapidly as speech is learned. This aspect of rehabilitation cannot be hurried. It resolves itself slowly when the patient learns to forget the past and brings hope and fortitude to the future.

\section{BIBLIOGRAPHY}

1. Bangs, Jack, L, Bibliography: Esophageal Speech. Jonrnal of Speech Disorders. 1947. Vol. 12 pp. 339-341.

2. Anderson, John, O. Bibliography on Oesophageal Speech. Journsl of Speech Disorders. 1954. Vol. 19, No. Speech. Journ

3. Bangs, J. "Speech after Laryngectomy". Journal of Speech Disorders. vol. 11. No. 3. Sept. 1946.

4. Sawkins, John. "Voice without a Larynx." The Medical Press. August, 1949.

5. Sommerville, A. "Speech Therapy for the Laryngectomee." South African Logopedic Society Congress Edition 1950. pp. 13-18.

6. Teaching Oesophageal Speech. News Bulletin of the College of Speech Therapists. July 1954. No. 46, pp. $4-8$.

7. Jacobson, Edmund. Progressive Relaxation. University of Chicago Press 1938. 2nd. Edit.

8. Nelson, Charles, R. Post Laryngectomy Speech. Funk and Wagnalls Co. New York, 1949.

9. Marland, $P$, M. "A Direct Method of Teaching Voice after Total Laryngectomy." Speech Vol. 3, 1949 . pp. 4-13.

\section{MisS BESSIE DEMBO}

54 WINGATE MANSIONS

Cor. SMIT \& NUGGET STREETS, HOSPITAL HILL, JOHANNESBURG

Phone 44-0860

Typing and Roneoing Undertaken, especially Theses and Students' Notes. 